\title{
EXPERIÊNCIAS DA RESIDÊNCIA PEDAGÓGICA NA ESCOLA DE TEMPO INTEGRAL CEM-CASTELO BRANCO
}

Pedagogical residency experiences at a full-time school CEM - Castelo Branco

Experiencias de la resindencia pedagogica en la escuela de tiempo completo CEM - Castelo Branco

\section{Miliane Moreira Cardoso Vieira ${ }^{1}$, Paulo Ricardo dos Santos Silva ${ }^{2}$, Jacques Janynne de} Santana Leão ${ }^{2}$, Sharon Elaine da S. G. Toledo ${ }^{3}$

${ }^{1}$ Docente do Curso de Graduação em Letras - Língua Inglesa e Literaturas, Universidade Federal do Tocantins, Araguaína, Brasil.

${ }^{2}$ Acadêmica, Letras-Língua Inglesa e Literaturas, UFT- Universidade Federal do Tocantins, Araguaína-Campus Cimba, Brasil.

${ }^{3}$ Professora da Educação Básica, Secretaria de Estado da Educação, Juventude e Esportes do Tocantins - SEDUC, Araguaína, Tocantins, Brasil

Artigo recebido em 03/04/2020 aprovado em 09/04/2020 publicado em 18/04/2020.

\section{INTRODUÇÃO}

Nesse presente trabalho serão abordadas as experiências das regências aplicadas em uma escola de Ensino Médio Cem Castelo Branco (CCB), que ocorreram no segundo semestre do ano de 2019. Neste período ocorreu a última fase de regências da Residência Pedagógica de Língua Inglesa.

O trabalho evidencia a importância de um ensino que possibilite os alunos a realizar uma absorção eficaz dos conteúdos e a desenvolver competências e habilidades da língua inglesa. De maneira que, os conteúdos se enquadrem com o contexto de vida dos alunos, partindo do local para o global.

Pois, é necessário que os alunos se sintam atraídos em poder obter o aprendizado da língua inglesa, de forma que venha fazer sentido na vida pessoal dos aprendizes como um todo. Caso contrário,

(...) o trabalho com habilidades linguísticas citadas, por diferentes razões, acaba centrando-se nos preceitos da gramática normativa (...) com certa razão, alunos e professores desmotivam-se, posto que o estudo abstrato do sistema sintático e morfológico de um idioma estrangeiro pouco interessa ou é capaz de despertar. (BRASIL, 2002, p.28).

Em meio a esses desafios, o professor pode tirar proveito adquirindo a si mesmo experiência e aprendizado. Utilizando propostas de ensino que tenham um melhor resultado, isto se a escola dispõe de equipamentos didáticos, que o permita ministrar aulas que fogem do modelo tradicional; que usam apenas a lousa e atividades do tipo fill in the blanks.

No entanto, acima de qualquer método específico ou teoria pedagógica de ensino, é importante que o profissional da educação, que decide trilhar por esse caminho da sala de aula, entenda que ele irá enfrentar situações diversas. Dentre os problemas, o professor pode ter que enfrentar o mau comportamento dos alunos e a falta de apoio escolar. A lista pode aumentar, porém ele deve entender que para uma mudança da realidade da educação, as atitudes devem começar dentro da sala de aula. Assim, como educadores precisamos 
buscar meios de garantir o interesse dos discentes, ao que está sendo ensinado.

\section{METODOLOGIAS E MATERIAIS}

No início da regência, dentre os problemas elencados acima, ainda tivemos que enfrentar mais um: a organização dos horários no início do semestre letivo. Isso atrapalhava o desenvolvimento, pois toda semana, tínhamos que ensinar em uma turma diferente e continuar o conteúdo que outro residente ou mesmo o professor preceptor já tinha começado.

Depois que o horário foi organizado, ficamos responsáveis por ministrar aulas em duas turmas, na 13.01 do primeiro ano e na 23.02 do segundo ano. Para ambas as turmas, decidimos abordar o tema transversal do Setembro Amarelo, em língua inglesa. Usamos nessa aula o data show para reprodução dos vídeos e do áudio e utilizamos cartazes feitos com cartolinas, para ministrar a aula.

Além dos dois recursos, foi usado também uma das salas equipadas com uma lousa digital e o espaço do laboratório de informática da escola. Primeiramente passamos um vídeo que fazia uma crítica ao excesso do uso de celular e das redes sociais em nossas vidas, em seguida era feito uma discussão a respeito do assunto. Após o vídeo, trabalhamos a leitura de um pequeno texto. Exploramos algumas frases e vocabulários que contextualizava com o tema depressão e setembro amarelo. Em relação ao trabalho com temas, podemos observar que:

O trabalho em torno de temas favorece o aprendizado, mesmo ocorrendo com projetos interdisciplinares. Se em Biologia está se tratando de alimentos geneticamente modificados, um texto em língua estrangeira pode abordar o mesmo tema em outro contexto, levando o aluno a observar, por exemplo, como se estrutura o texto técnico-científico. (BRASIL, 2007, p.109)

Ao fim da aula propomos uma dinâmica na qual os alunos deveriam tentar introduzir um palito de dente em um balão, mas sem estourá-lo. Depois de várias tentativas sem sucesso. Os alunos chegaram a conclusão que para que o balão não estourasse, era preciso introduzir o palito apenas na ponta do balão. Explicamos que o balão representava a vida dos alunos e os palitos seus problemas.

A moral da dinâmica era que eles deveriam exercer a prática da resiliência, e que eles eram capazes e fortes o suficiente para evitar que os problemas da vida não os impedissem de viver. Deixando claro que dependendo da gravidade é preciso procurar os profissionais adequados para essas questões. Evidenciando que, não está na competência do professor ter a solução para todos os problemas.

\section{RESULTADOS E DISCUSSÃO}

A aula em destaque teve um ótimo resultado, pois a maioria dos alunos participou ativamente das atividades. A temática contribuiu bastante em despertar o interesse deles. Temas como depressão e tristeza são sentimentos que estão muito próximos da realidade de todos.

O fato é que muitos estudantes vão à escola com muitos problemas e dilemas que um adolescente enfrenta, principalmente problemas 
familiares e pessoais. Daí a questão: o que o professor deve fazer em situações como essa? Já que na maioria das vezes ele não recebe assistência da escola e do sistema educacional como um todo?

Em geral, as regências ocorridas ao longo da residência pedagógica nos permitiu dar uma olhada além da sala de aula, principalmente na relação aluno / professor / conteúdo. Evidenciando que ensinar é muito mais do que entrar na sala de aula, explicar o assunto e desejar que o aluno simplesmente absorva tudo o que está sendo dito de maneira passiva.

É verdade, também, que os professores se estressam com alunos indisciplinados e alunos que não participam das aulas. No entanto, mas o professor precisa se atentar e saber como lidar com as adversidades que a sala de aula pode oferecer.

Assim, cabe aos professores criar situações que facilitem a conscientização, a construção de valor e a identidade moral e cívica, além de desenvolver habilidades que possam:

- prevenir a violência na escola e fora dela;

- lutar contra preconceitos sexuais, étnicos e sociais e discriminação;

- participar da criação de regras de vida comuns relacionadas a disciplinas escolares, sanções e avaliação de conduta;

- analisar a relação pedagógica, autoridade e comunicação em sala de aula;e

- desenvolver um senso de responsabilidade, solidariedade e senso de justiça. (BRASIL, 2007, p.133)

No que diz respeito a aplicação das aulas, é preciso destacar que a escola tinha a vantagem de ter disponível certos recursos didáticos. Isso permitiunos ministrar essa e outras aulas com uma melhor qualidade. A escola nos disponibilizou: o laboratório de informática, um quite multimídia e uma sala com uma lousa digital. Sobre a importância de aplicar tecnologias da informação:

A aplicação de tecnologias da informação amplia as possibilidades de busca de informações em outro idioma. No caso do Inglês, é importante considerar também que conhecimentos da língua são instrumentos de acesso ao ciberespaço, uma vez que grande parte do vocabulário usual da informática emprega a língua inglesa, idioma que também predomina nos sites da internet. (BRASIL, 2007, p.100)

Na realização de nossas regências não foi possível fazer uso do livro didático. Por isso, tivemos que adaptar os conteúdos de acordo com os recursos que tínhamos em mãos. De maneira que os alunos pudessem compreender e interagir adequadamente. Esta aula sobre o setembro amarelo foi um exemplo disso, pois com o auxílio dos recursos tecnológicos e outros materiais diversos, que a escola dispusera. Além disso, conectamos a língua inglesa com uma temática de cunho sociológico, o que contribuiu positivamente na aula.

\section{CONCLUSÃO}

Ao finalizar as regências no CEM - Castelo Branco, pode-se concluir, que houve um excelente desenvolvimento em nossas habilidades de ensino. Mesmo havendo certos desafios que nos obrigou a sair da zona de conforto, para poder aplicar uma regência de qualidade.

Como professores a habilidade mais desenvolvida foi com o manuseio dos recursos tecnológicos, como a criação de slides através do Power Point, aprendemos a usar muito bem a lousa digital e o quite multimídia. Ter disponível o laboratório de informática e a sala com a lousa 
digital favoreceu no planejamento de algumas aulas. A aquisição desses recursos é importante porque a ciência da computação e demais mídias eletrônicas são ferramentas que podem auxiliar no ensino/aprendizagem de línguas estrangeiras (BRASIL, 2007).

Confiança foi algo que também melhorou ao longo deste período, pois durante as regências apareceram vários problemas. No entanto, a relação com os alunos foi perdendo aquela tensão inicial, devido ao contato semanal que tínhamos com eles. Aprendemos que, é muito importante que o professor consiga desenvolver um relacionamento de harmonia. Assim, ele pode ser respeitado na sala de aula, exercendo autoridade sem precisar do uso do autoritarismo.

Enfrentamos situações complexas de grande responsabilidade, como conciliar a residência pedagógica com as demais atividades da universidade. Mas, concluímos as regências com a satisfação de ter conseguido superar todos esses desafios que enfrentamos. Não apenas isso, mas também por toda a bagagem acumulada nessa experiência.

Diante disso, constatamos que a sala de aula não é um circo de horrores, como geralmente pensamos. Se tivermos a oportunidade de trabalharmos como professores, teremos em mãos a experiência necessária para assim poder realizá-la.

Todos os autores declararam não haver qualquer potencial conflito de interesses referente a este artigo.

\section{REFERÊNCIAS}

BRASIL. Orientações Educacionais Complementares Aos Parâmetros Curriculares Nacionais (PCN+ Ensino Médio). Linguagens, Códigos e suas Tecnologias. Brasília: MEC, 2002.

BRASIL. Parâmetros Curriculares Nacionais+ Ensino Médio. Linguagens, Códigos e suas tecnologias. Brasília: MEC, 2007. 